\title{
Exploring chromosomal abnormalities and genetic changes in uterine smooth muscle tumors
}

Bernadette Liegl-Atzwanger ${ }^{1}$, Ellen Heitzer ${ }^{2}$, Karin Flicker ${ }^{2}$, Stephanie Müller ${ }^{2}$, Peter Ulz ${ }^{2}$, Ozlen Saglam ${ }^{3}$, Fattaneh Tavassoli ${ }^{3}$, Mojgan Devouassoux-Shisheboran ${ }^{4}$, Jochen Geigl ${ }^{2}$ and Farid Moinfar ${ }^{5}$

${ }^{1}$ Institute of Pathology, Medical University of Graz, Graz, Austria; ${ }^{2}$ Department of Human Genetics, Medical University of Graz, Graz, Austria; ${ }^{3}$ Department of Pathology, Yale University School of Medicine, New Haven, CT, USA; ${ }^{4}$ Department of Pathology, Hospices Civilis de Lyon, Lyon, France and ${ }^{5}$ Department of Pathology, Hospital of the Sisters of Charity, Linz, Austria

\begin{abstract}
Smooth muscle tumors of the uterus are a diagnostically challenging group of tumors. Molecular surrogate markers reliably distinguishing between benign and malignant tumors are not available. Therefore, the diagnosis is based on morphologic criteria. The aim was to investigate a well-characterized group of challenging uterine smooth muscle tumors consisting of 20 leiomyomas, 13 leiomyomas with bizarre nuclei, and 14 leiomyosarcomas for copy number alterations, MED12 mutations and $F H$ deletions to search for potential diagnostically useful surrogate markers. MED12 mutations were detected in 47,15 , and $25 \%$ of leiomyomas, leiomyomas with bizarre nuclei and leiomyosarcomas, respectively. MED12 mutations in leiomyomas with bizarre nuclei were detected outside the hotspot region. FH-deletions were seen in $27,30.8$, and $25 \%$ of leiomyomas, leiomyomas with bizarre nuclei and leiomyosarcomas, respectively. By using copy number alteration profiling a clear separation of leiomyomas, leiomyomas with bizarre nuclei and leiomyosarcomas could not be observed. Copy number alterations revealed clear genetic similarities between leiomyomas with bizarre nuclei and leiomyosarcomas. Leiomyosarcomas showed a similar pattern of gains and losses as leiomyomas with bizarre nuclei, with additional copy number alterations and more homozygous losses and high-level amplifications compared to leiomyomas with bizarre nuclei. In conclusion, this study demonstrates that known FH-deletions, a recurrent molecular change in leiomyomas, occur in morphologically challenging variants of leiomyomas, leiomyomas with bizarre nuclei and leiomyosarcomas. Although MED12 mutations are common in leiomyomas, they infrequently occur in leiomyomas with bizarre nuclei and leiomyosarcomas. The genetic similarities between leiomyomas with bizarre nuclei and leiomyosarcomas raise the intriguing possibility that uterine leiomyomas with bizarre nuclei and leiomyosarcomas are closely related and challenge the traditional concept that leiomyoma with bizarre nuclei is a tumor with just marked 'degenerative' cellular changes. These findings support the hypothesis that tumor progression within uterine smooth muscle tumors might occur.
\end{abstract} Modern Pathology (2016) 29, 1262-1277; doi:10.1038/modpathol.2016.107; published online 1 July 2016

\section{Introduction}

Smooth muscle tumors are the most common mesenchymal tumors of the uterus. Approximately $70 \%$ of

Correspondence: Professor Dr B Liegl-Atzwanger, Institute of Pathology, Medical University of Graz, Graz, Austria.

E-mail: bernadette.liegl-atzwanger@medunigraz.at or Professor Dr E Heitzer, Department of Human Genetics, Medical University Graz, Graz, Austria.

E-mail: ellen.heitzer@medunigraz.at or Professor Dr F Moinfar, Department of Pathology, Hospital of the Sisters of Charity, Linz, Austria.

E-mail: farid.moinfar@bhs.at

Received 13 January 2016; revised 25 April 2016; accepted 25 April 2016; published online 1 July 2016 women develop uterine leiomyomas and a quarter of them suffer from substantial clinical symptoms. ${ }^{1}$ In contrast, though uterine leiomyosarcomas are rare, they are the most common sarcomas of the uterine body. Overall smooth muscle neoplasms are a heterogeneous, diagnostically challenging group of tumors with benign, malignant and intermediate tumor categories not infrequently causing diagnostic problems. Over the years a number of different morphologic tumor subtypes have been described. The benign uterine smooth muscle neoplasms include leiomyoma of usual type, cellular leiomyoma, ${ }^{2}$ mitotically active leiomyoma,${ }^{3}$ leiomyoma with bizarre nuclei (synonyms: 'pleomorphic/symplastic' leiomyoma and previously termed atypical 
leiomyoma according to the WHO 2003) ${ }^{4-7}$ leiomyoma with secondary hormonal changes, ${ }^{8}$ leiomyoma with hydropic degeneration, ${ }^{9}$ apoplectic leiomyoma ${ }^{10}$ and rare subtypes like plexiform leiomyoma, ${ }^{3}$ epithelioid leiomyoma, ${ }^{11}$ myxoid leiomyoma ${ }^{12}$ lipoleiomyoma, ${ }^{13,14}$ leiomyoma with hematopoietic elements, ${ }^{15}$ and neurilemmoma (schwannoma)-like leiomyoma. ${ }^{16}$ Leiomyomas mainly occur in women of reproductive age with a frequency as high as $77 \%$ if hysterectomy specimens are carefully investigated. ${ }^{3}$ In addition, there is strong evidence that these tumors are hormonally responsive and dependent.

From a molecular standpoint, leiomyomas are thought to represent separate clonal neoplasms arising independently from leiomyosarcoma within the uterus. ${ }^{17}$ Approximately half of leiomyomas are reported to have a normal karyotype on conventional cytogenetic analysis and the rest are characterized by a simple karyotype showing deletion of $7 \mathrm{q}, \mathrm{t}(12 ; 14)$, duplication of chromosome 12, and rearrangements involving $6 p, 3 q$ and $10 q .{ }^{18}$ The wide range of chromosomal alterations indicates that multiple different pathogenic mechanisms may be involved in tumor formation. Although in general, specific genetic patterns do not correlate with morphology, deletions of $1 p$ have been reported to be associated with cellular and atypical morphology. ${ }^{19}$

Leiomyosarcomas account for $<2 \%$ of all uterine malignancies. ${ }^{20,21}$ They occur in the fifth and sixth decades of life presenting with symptoms like dysfunctional uterine bleeding and pelvic pain. ${ }^{22,23}$ Uterine leiomyosarcomas are aggressive tumors with a tendency to recur locally and metastasize mainly to the lung and liver. The 5-year survival rate varies between 45 and $60 \% .^{22-25}$

Despite a number of molecular studies, the pathogenesis of uterine smooth muscle neoplasms needs further exploration, and reliable biomarkers to clearly separate diagnostically challenging cases are missing. Therefore, assessment of malignancy in uterine smooth muscle neoplasms is based on a landmark study by Bell et $a l^{3}$ using purely morphologic criteria. The crucial features include nuclear atypia, mitotic figures per $10 \mathrm{hpf}$, and the presence or absence of coagulative tumor cell necrosis. ${ }^{3}$ The diagnosis of malignancy is based on a combination of these criteria. Tumors short on these criteria are diagnosed as smooth muscle tumors of uncertain malignant potential. ${ }^{6,26,27}$

Molecular data are available for uterine spindle cell leiomyosarcomas and leiomyosarcomas in soft tissues demonstrating variable cytogenetically complex numerical and structural changes of tumors, highlighting the degree of genomic instability. ${ }^{28,29}$ Frequent loss of heterozygosity particularly for chromosomes 10 and 13 has been described. ${ }^{30,31}$

Recently, the first recurrent somatic mutations of the Mediator Subcomplex 12 gene (MED12) have been demonstrated in benign and malignant uterine $^{32,33}$ and extrauterine smooth muscle tumors $^{34}$ indicating that MED12 mutations have a crucial role in tumors with smooth muscle differentiation. In addition, Fumarate Hydratase (FH)deletions and rearrangements of high motility group protein 2 (HMGA2) have been proposed as independent somatic driver mutations in leiomyoma. ${ }^{35-37}$

The focus of this study was to explore copy number alterations, MED12 mutational status, and $\mathrm{FH}$-deletions in diagnostically challenging smooth muscle tumors with special emphasis on leiomyoma with bizarre nuclei, hormonally treated leiomyoma and uterine leiomyosarcoma.

\section{Materials and Methods}

\section{Tumor Samples and Immunophenotyping}

Twenty leiomyomas obtained from 15 patients including leiomyoma of usual type $(n=10)$, hormonally treated leiomyoma $(n=6)$, cellular leiomyoma $(n=1)$, leiomyoma with very focal atypia (defined by very few isolated cells with degenerative nuclear atypia) $(n=2)$, leiomyoma with prominent vascularity and edema $(n=1)$, as well as leiomyoma with bizarre nuclei $(n=13)$ obtained from 13 patients and leiomyosarcoma $(n=14)$, including tissue from metastatic site, obtained from 8 patients (Tables 1, 2, and 3) were retrieved from the pathology archives of the Medical University of Graz, Austria, Yale University, USA and "Hospices Civilis de Lyon", Lyon, France. Four-micron hematoxylin and eosin stained sections generated from formalin-fixed paraffin embedded tissue were reviewed to confirm the diagnoses before inclusion in the study. Two pathologists (BLA, FM) independently reevaluated all cases for the following histologic features: type of margin (circumscribed or infiltrative), cell types (epithelioid, spindled, multinucleated), cytologic atypia (mild, moderate, severe), degenerative nuclear atypia, necrosis (absent, present, ischemic or coagulative), vascular invasion (absent, present), and mitotic rate (expressed as the number of mitotic figures per 10 high power fields (hpfs) in the most mitotically active area, using a $40 \times$ objective and a $10 \times$ ocular, field size $0.25 \mathrm{~mm}^{2}$ ) (Tables 1, 2, and 3). Only unequivocal cases where both investigators came up with the identical diagnosis (leiomyoma, leiomyoma with bizarre nuclei, or leiomyosarcoma) were included in this study. No smooth muscle tumors with uncertain malignant potential were included in this study. We additionally performed immunohistochemical studies in all cases; the antibodies, clones, dilutions, pretreatment conditions, and sources are listed in Supplementary Table 4. We used the Envision Plus detection system (Dako, Carpinteria, CA, USA) for all antibodies. Appropriate positive and negative controls were included.

\section{DNA Isolation}

For DNA extraction, $10 \mu \mathrm{m}$ sections were cut, tumor areas of interest were marked and manually 
Table 1 Leiomyoma: overview of clinical data, morphology, and genetics

\begin{tabular}{|c|c|c|c|c|c|c|c|c|c|c|c|}
\hline $\begin{array}{l}\text { Patient } \\
\text { No. }\end{array}$ & Tumor samples & $\begin{array}{l}\text { No. of available } \\
\text { tumors }\end{array}$ & Age & Size $(\mathrm{cm})$ & Clinical history & Procedure & Diagnosis & $\begin{array}{c}\text { Mitoses/ } \\
10 \mathrm{hpf}\end{array}$ & Necrosis & MED12 mutation & $\begin{array}{l}\mathrm{FH} \\
\text { deletion }\end{array}$ \\
\hline 1 & Leiomyoma 1 & 1 & 45 & 12 & Fibroid & Hysterectomy & Leiomyoma & $0-1$ & Absent & Negative & FHdel \\
\hline 2 & Leiomyoma 2 & 1 & 67 & 2.2 & Bleeding & Hysterectomy & Leiomyoma & $0-1$ & Absent & Negative & FHdel \\
\hline \multirow[t]{2}{*}{3} & Leiomyoma 3_1 & $\begin{array}{c}2 \text { samples from } 2 \\
\text { different tumors }\end{array}$ & 41 & 0.8 & Fibroid & Hysterectomy & Leiomyoma & 0 & Absent & c. $131 \mathrm{G}>\mathrm{T}, \mathrm{p} . \mathrm{G} 44 \mathrm{~V}$ & \\
\hline & Leiomyoma 3_2 & & 41 & 0.6 & Fibroid & Hysterectomy & Leiomyoma & 0 & Absent & c.131G > A, p.G44D & \\
\hline \multirow[t]{2}{*}{4} & Leiomyoma 4_1 & $\begin{array}{l}2 \text { samples from } 2 \\
\text { different tumors }\end{array}$ & 39 & 8 & Fibroid & Hysterectomy & Leiomyoma & 0 & Absent & Negative & \\
\hline & Leiomyoma 4_2 & & 39 & 6 & Fibroid & Hysterectomy & Leiomyoma & 0 & Absent & Negative & \\
\hline \multirow[t]{2}{*}{5} & Leiomyoma 5_1 & $\begin{array}{l}2 \text { samples from } 2 \\
\text { different tumors }\end{array}$ & 41 & 0.7 & Fibroid & Hysterectomy & Leiomyoma & 0 & Absent & c.131G > A, p.G44D & \\
\hline & Leiomyoma 5_1 & & 41 & 1 & Fibroid & Hysterectomy & Leiomyoma & 0 & Absent & c. $131 \mathrm{G}>$ A, p.G44D & \\
\hline 6 & Leiomyoma 6 & 1 & 32 & 3 & Uterine mass & Hysterectomy & Leiomyoma & 0 & Absent & Negative & \\
\hline $7 a$ & Leiomyoma 7_2 & individual tumor & 42 & 2 & Menorrhagia & Hysterectomy & Leiomyoma & $0-1$ & Absent & Negative & FHdel \\
\hline 8 & Leiomyoma 8 & 1 & 52 & Not known & $\begin{array}{l}\text { Enlarging pelvic } \\
\text { mass }\end{array}$ & Hysterectomy & $\begin{array}{l}\text { Leiomyoma with } \\
\text { edema and prominent } \\
\text { vasculature }\end{array}$ & $0-1$ & Absent & Negative & FHdel \\
\hline 9 & Leiomyoma 9 & 1 & 37 & 14.3 & Lupron treatment & Myomectomy & Leiomyoma & $0-1$ & Present & c.100-10del10 & \\
\hline 10 & Leiomyoma 10 & 1 & 37 & 0.3 & Lupron treatment & Myomectomy & Leiomyoma & $0-1$ & Absent & c. $100-64 \mathrm{G}>\mathrm{A}$ & \\
\hline \multirow[t]{2}{*}{11} & Leiomyoma 11_1 & $\begin{array}{l}2 \text { samples from } \\
\text { the same tumor }\end{array}$ & 41 & 3.8 & Lupron treatment & Myomectomy & Leiomyoma & $0-2$ & Present & c. $131 G>$ A, p.G44D & \\
\hline & Leiomyoma 11_2 & & 41 & 3.8 & Lupron treatment & Myomectomy & Leiomyoma & 2 & Present & c.131G > A, p.G44D & \\
\hline 12 & Leiomyoma 12 & 1 & 40 & 10 & $\begin{array}{l}\text { Parasitic fibroid, } \\
\text { suprapubic mass } \\
\text { Lupron treatment }\end{array}$ & Myomectomy & Leiomyoma & $0-1$ & Present & c. $131 G>$ A, p.G44D & \\
\hline 13 & Leiomyoma 13 & 1 & 32 & 12 & Lupron treatment & Myomectomy & Leiomyoma & $0-1$ & Present & c.130G > A, p.G44S & \\
\hline 14 & Leiomyoma 14 & 1 & 51 & Not known & Bleeding & Hysterectomy & Cellular leiomyoma & $0-1$ & Absent & Negative & \\
\hline 15 & Leiomyoma 15 & 1 & 61 & 2.2 & Benign ovarian mass & Hysterectomy & $\begin{array}{l}\text { Leiomyoma with } \\
\text { focal atypia }\end{array}$ & $0-1$ & Absent & c.107 T>G, p.L36R & \\
\hline $7 \mathrm{~b}$ & Leiomyoma 7_1 & Individual tumor & 42 & 0.5 & Menorrhagia & Hysterectomy & $\begin{array}{l}\text { Leiomyoma with } \\
\text { focal atypia, bilateral } \\
\text { ovarian teratoma }\end{array}$ & $0-1$ & Absent & Negative & \\
\hline
\end{tabular}


Table 2 Leiomyoma with bizzare nuclei: overview of clinical data, morphology, and genetics

\begin{tabular}{|c|c|c|c|c|c|c|c|c|c|c|c|c|}
\hline $\begin{array}{l}\text { Patient } \\
\text { no. }\end{array}$ & Tumor sample & $\begin{array}{l}\text { No. of available } \\
\text { tumors }\end{array}$ & Age & Size $(\mathrm{cm})$ & $\begin{array}{l}\text { Clinical } \\
\text { history }\end{array}$ & Procedure & Diagnosis & $\begin{array}{l}\text { Mitoses/ } \\
10 \mathrm{hpf}\end{array}$ & Necrosis & MED12 mutation & FH deletion & Follow up \\
\hline 1 & $\begin{array}{l}\text { Leiomyoma with } \\
\text { bizzare nuclei } 1\end{array}$ & 1 & 49 & 10 & $\begin{array}{l}\text { Rapidly } \\
\text { growing } \\
\text { tumor }\end{array}$ & Hysterectomy & $\begin{array}{l}\text { Leiomyoma with } \\
\text { bizzare nuclei }\end{array}$ & 2 & Present & Negative & & NA \\
\hline 2 & $\begin{array}{l}\text { Leiomyoma with } \\
\text { bizzare nuclei } 2\end{array}$ & 1 & 36 & 20 & Pelvic mass & Hysterectomy & $\begin{array}{l}\text { Leiomyoma with } \\
\text { bizzare nuclei }\end{array}$ & $1-2$ & Absent & Negative & FHdel & NA \\
\hline 3 & $\begin{array}{l}\text { Leiomyoma with } \\
\text { bizzare nuclei } 3\end{array}$ & 1 & 30 & 8.5 & Fibroid & Myomectomy & $\begin{array}{l}\text { Leiomyoma with } \\
\text { bizzare nuclei }\end{array}$ & $0-1$ & Absent & Negative & FHdel & NA \\
\hline 4 & $\begin{array}{l}\text { Leiomyoma with } \\
\text { bizzare nuclei } 4\end{array}$ & 1 & 40 & 7 & Fibroid & Hysterectomy & $\begin{array}{l}\text { Leiomyoma with } \\
\text { bizzare nuclei }\end{array}$ & 2 & Absent & Negative & FHdel & $66 \mathrm{mo}$ \\
\hline 5 & $\begin{array}{l}\text { Leiomyoma with } \\
\text { bizzare nuclei } 5\end{array}$ & 1 & 45 & 2.5 & Fibroid & Hysterectomy & $\begin{array}{l}\text { Leiomyoma with } \\
\text { bizzare nuclei }\end{array}$ & 4 & Absent & Negative & & $94 \mathrm{mo}$ \\
\hline 6 & $\begin{array}{l}\text { Leiomyoma with } \\
\text { bizzare nuclei } 6\end{array}$ & 1 & 67 & 3 & Bleeding & Hysterectomy & $\begin{array}{l}\text { Leiomyoma with } \\
\text { bizzare nuclei }\end{array}$ & $0-1$ & Absent & Negative & & $14 \mathrm{mo}$ \\
\hline 7 & $\begin{array}{l}\text { Leiomyoma with } \\
\text { bizzare nuclei } 7\end{array}$ & 1 & 50 & 7 & Fibroid & Hysterectomy & $\begin{array}{l}\text { Leiomyoma with } \\
\text { bizzare nuclei }\end{array}$ & 2 & Absent & Negative & & $74 \mathrm{mo}$ \\
\hline 8 & $\begin{array}{l}\text { Leiomyoma with } \\
\text { bizzare nuclei } 8\end{array}$ & 1 & 74 & 7 & Fibroid & Hysterectomy & $\begin{array}{l}\text { Leiomyoma with } \\
\text { bizzare nuclei }\end{array}$ & $0-1$ & Absent & NA & & $60 \mathrm{mo}$ \\
\hline 9 & $\begin{array}{l}\text { Leiomyoma with } \\
\text { bizzare nuclei } 9\end{array}$ & 1 & 73 & 2.5 & Fibroid & Hysterectomy & $\begin{array}{l}\text { Leiomyoma with } \\
\text { bizzare nuclei }\end{array}$ & 2 & Absent & c. $122 \mathrm{~T}>\mathrm{C}, \mathrm{p} . \mathrm{V} 41 \mathrm{~A}$ & & $50 \mathrm{mo}$ \\
\hline 10 & $\begin{array}{l}\text { Leiomyoma with } \\
\text { bizzare nuclei } 10\end{array}$ & 1 & 36 & 5.5 & Fibroid & Hysterectomy & $\begin{array}{l}\text { Leiomyoma with } \\
\text { bizzare nuclei }\end{array}$ & 2 & Absent & c.156T > C, p. $(=)$ & & $105 \mathrm{mo}$ \\
\hline 11 & $\begin{array}{l}\text { Leiomyoma with } \\
\text { bizzare nuclei } 11\end{array}$ & 1 & 50 & 5 & Fibroid & Hysterectomy & $\begin{array}{l}\text { Leiomyoma with } \\
\text { bizzare nuclei }\end{array}$ & 5 & Absent & NA & & NA \\
\hline 12 & $\begin{array}{l}\text { Leiomyoma with } \\
\text { bizzare nuclei } 12\end{array}$ & 1 & 38 & Not known & Fibroid & Myomectomy & $\begin{array}{l}\text { Leiomyoma with } \\
\text { bizzare nuclei }\end{array}$ & 3 & Absent & NA & & NA \\
\hline 13 & $\begin{array}{l}\text { Leiomyoma with } \\
\text { bizzare nuclei } 13\end{array}$ & 1 & 32 & 4 & Uterine mass & Hysterectomy & $\begin{array}{l}\text { Leiomyoma with } \\
\text { bizzare nuclei }\end{array}$ & 4 & Absent & Negative & FHdel & NA \\
\hline
\end{tabular}

Abbreviations: mo, month free of disease; NA, not available. 
Table 3 Leiomyosarcoma: overview of clinical data, morphology, and genetics

\begin{tabular}{|c|c|c|c|c|c|c|c|c|c|c|c|c|}
\hline $\begin{array}{l}\text { Patient } \\
\text { no. }\end{array}$ & Tumor sample & $\begin{array}{l}\text { No. of available } \\
\text { tumors }\end{array}$ & Age & Size $(\mathrm{cm})$ & Clinical history & Procedure & Diagnosis & $\begin{array}{l}\text { Mitoses/ } \\
10 \text { hpf }\end{array}$ & Necrosis & $\begin{array}{l}\text { MED12 } \\
\text { mutation }\end{array}$ & $\begin{array}{l}\mathrm{FH} \\
\text { deletion }\end{array}$ & Follow up \\
\hline \multirow[t]{3}{*}{1} & Leiomyosarcoma 1_1 & \multirow[t]{3}{*}{$\begin{array}{l}3 \text { sample from } \\
3 \text { tumors }\end{array}$} & 51 & Not known & $\begin{array}{l}\text { Primary, enlarged } \\
\text { uterus }\end{array}$ & Hysterectomy & Leiomyosarcoma (G3) & 43 & Present & \multicolumn{2}{|l|}{$\begin{array}{l}\text { c. } 131 G>A, \\
\text { p.G44D }\end{array}$} & NA \\
\hline & Leiomyosarcoma 1_2 & & 51 & Not known & Metastasis after 4a & Metastasectomy & $\begin{array}{l}\text { Leiomyosarcoma } \\
\text { metastasis }\end{array}$ & 35 & Present & & \\
\hline & Leiomyosarcoma 1_3 & & 51 & Not known & Metastasis after 7a & Metastasectomy & $\begin{array}{l}\text { Leiomyosarcoma } \\
\text { metastasis omentum }\end{array}$ & 39 & Present & \multicolumn{2}{|l|}{ Negative } & \\
\hline 2 & Leiomyosarcoma 2 & 1 & 80 & 8 & $\begin{array}{l}\text { Primary uterus, } \\
\text { enlarged uterus, } \\
\text { LMS with } \\
\text { osteoclastic giant } \\
\text { cells }\end{array}$ & Hysterectomy & $\begin{array}{l}\text { Leiomyosarcoma } \\
\text { with osteoclastic } \\
\text { giant cells (G3) }\end{array}$ & 18 & Present & \multicolumn{2}{|l|}{ NA } & NA \\
\hline 3 & Leiomyosarcoma 3 & 1 & 59 & 8 & $\begin{array}{l}\text { Primary uterus, } \\
\text { postmenopausal } \\
\text { bleeding }\end{array}$ & Hysterectomy & $\begin{array}{l}\text { Leiomyosarcoma } \\
\text { with epitheloid } \\
\text { features and clear cell } \\
\text { changes (G3) }\end{array}$ & 35 & Present & \multicolumn{2}{|l|}{ Negative } & NA \\
\hline 4 & Leiomyosarcoma 4 & 1 & 57 & 10 & Primary uterus & Hysterectomy & $\begin{array}{l}\text { Leiomyosarcoma (G2) } \\
\text { and incidental } \\
\text { endometrioid } \\
\text { carcinoma }\end{array}$ & 2 & Present & \multicolumn{2}{|l|}{$\begin{array}{l}\text { c.131G >C, } \\
\text { p.G44A het }\end{array}$} & DD \\
\hline 5 & Leiomyosarcoma 5 & 1 & 46 & 5 & Primary uterus & Hysterectomy & Leiomyosarcoma (G3) & 32 & Absent & \multirow{2}{*}{\multicolumn{2}{|c|}{$\begin{array}{l}\text { Negative } \\
\text { NA }\end{array}$}} & DD \\
\hline 6 & Leiomyosarcoma 6 & 1 & 51 & 9 & Primary uterus & Hysterectomy & Leiomyosarcoma (G3) & 12 & Present & & & DD \\
\hline \multirow[t]{2}{*}{7} & Leiomyosarcoma 7_1 & \multirow{2}{*}{$\begin{array}{l}2 \text { sample from } \\
\text { the same tumor }\end{array}$} & 61 & 10 & Primary uterus & Hysterectomy & Leiomyosarcoma (G3) & 19 & Present & Negative & NA & DD \\
\hline & Leiomyosarcoma 7_2 & & 61 & 10 & \multirow{5}{*}{ Primary uterus } & Hysterectomy & Leiomyosarcoma (G3) & 27 & Present & \multirow{2}{*}{\multicolumn{2}{|c|}{$\begin{array}{ll}\text { Negative } & \text { FHdel } \\
\text { c.204+58G }>\text { C FHdel } \\
\text { het }\end{array}$}} & \\
\hline \multirow[t]{4}{*}{8} & Leiomyosarcoma 8_1 & \multirow{4}{*}{$\begin{array}{l}\text { 4 samples from } \\
\text { the same tumor }\end{array}$} & 58 & 14 & & Hysterectomy & Leiomyosarcoma (G3) & 22 & Present & & & \multirow[t]{4}{*}{ DD } \\
\hline & Leiomyosarcoma 8_2 & & 58 & 14 & & Hysterectomy & Leiomyosarcoma (G3) & 25 & Present & $\begin{array}{l}\text { c. } 204+58 \mathrm{G}>\mathrm{C} \\
\text { het }\end{array}$ & FHdel & \\
\hline & Leiomyosarcoma 8_3 & & 58 & 14 & & Hysterectomy & Leiomyosarcoma (G3) & 18 & Present & $\begin{array}{l}\text { c. } 204+58 G>C \\
\text { het }\end{array}$ & FHdel & \\
\hline & Leiomyosarcoma 8_4 & & 58 & 14 & & Hysterectomy & Leiomyosarcoma (G3) & 17 & Present & $\begin{array}{l}\text { c. } 204+58 G>C \\
\text { het }\end{array}$ & FHdel & \\
\hline
\end{tabular}

Abbreviations: DD, died of disease; NA, not available. 
needle-microdissected. DNA extraction was performed with a DNA isolation kit (Qiagen) according to the protocol 'Isolation of genomic DNA from formalin-fixed paraffin embedded tissue sections'. The quality of the DNA was evaluated using a multiplex PCR approach. ${ }^{38,39}$ Samples with three or four bands on a $1.5 \%$ agarose gel were used for array-CGH analysis.

\section{Array CGH}

Array CGH detects copy number changes in a test DNA compared to a reference DNA at a high resolution. For this study 60k arrays from Agilent Technologies were used. Samples were labeled with the Bioprime ArrayCGH Genomic Labeling System (Invitrogen, Carlsbad, CA, USA) according to the manufacturer's instructions. Briefly, $500 \mathrm{ng}$ test DNA and reference DNA (Promega, Mannheim, Germany) was differentially labeled with dCTP-Cy5 or dCTP-Cy3 (GE Healthcare, Piscataway, NJ, USA). Slides were scanned using a microarray scanner (Agilent Technologies, Santa Clara, CA, USA). Data normalization and calculation of ratio values were conducted employing Feature Extraction software from Agilent Technologies. Data analysis was performed using the software Genomic Workbench 5.0.14 (statistical algorithm: ADM-2; alteration threshold: 8.0; moving average window: $2 \mathrm{MB}$; Fuzzy zero: off; consecutive clone filter: 10) from Agilent Technologies. Log ratios higher/lower 0.3 were considered as copy number change.

\section{Mutational Analysis of MED12}

MED12 exon 2 was amplified using Qiagen HotStart PCR MasterMix (Qiagen, Hilden, Germany) with primers MED12_E2_F: 5'-TTCTACACGGAACCCTC CTC-3' and MED12_E2_R: 5'-GGCAAACTCAGCCAC TTAGG-3') according to the manufacturer's recommendations. Briefly, we used $0.5 \mu \mathrm{l}$ of DNA (corresponding to $20-50 \mathrm{ng}$ ), $1 \mu \mathrm{l}$ of $10 \mu \mathrm{m}$ primer in a final reaction volume of $11 \mu \mathrm{l}$. After diluting the PCR product 1:2,1 $\mu \mathrm{l}$ was directly used for sequencing using Big Dye Terminator v3.1 Cycle Sequencing Kit in a final volume of $10 \mu \mathrm{l}$ with $0.4 \mu \mathrm{l}$ of $10 \mathrm{mM}$ primers. Sequencing reactions were purified using Sephadex. Both DNA strands were sequenced on an ABI3130 Genetic Analyzer and mutations on one strand were always confirmed on the opposite strand. DNA sequence analysis was performed using SeqScape software (Applied Biosystems, Carlsbad, CA, USA). Sequences were aligned according to RefSeq entry NM_005120.

\section{Statistics}

To summarize copy number alterations of samples and to identify overlapping copy number alterations within each sample group, we subjected our data to the Genomic Recurrent Event Viewer (GREVE) algorithm. ${ }^{40}$ In order to identify recurrent changes, the tumor sample with the highest amount of copy number alterations was selected of those patients with two or more samples. Details on settings of the software parameters are available on request.

Comparison of the percentage of aberrant genomic regions for each subgroup was performed in $\mathrm{R}$ using the wilcox.test function. ${ }^{41} \log 2$-ratios from the arrayCGH raw data were clustered hierarchically by the hclust function of $\mathrm{R}$ using Manhattan distance in order to identify phylogenetic relationships between copy number profiles of leiomyomas, leiomyomas with bizarre nuclei, leiomyosarcomas, and tumor samples from the same patients in a distance matrix (from Manhattan distances). ${ }^{41}$

\section{Results}

\section{Clinical Features}

The clinical features of the 36 patients in our study are summarized in Tables 1,2, and 3 . The age at presentation ranged from 32 to 67 years (median age 44 years), from 30 to 74 years (median age 48 years), and from 46 to 80 years (median age 58 years) in the leiomyoma, leiomyoma with bizarre nuclei, and leiomyosarcoma groups, respectively. The tumor size ranged from 0.3 to $12 \mathrm{~cm}$ (median size $5 \mathrm{~cm}$ ), from 2.5 to $20 \mathrm{~cm}$ (median size $7 \mathrm{~cm}$ ), and from 5 to $14 \mathrm{~cm}$ (median size $9 \mathrm{~cm}$ ) in the leiomyoma, leiomyoma with bizarre nuclei, and leiomyosarcoma groups, respectively. In the leiomyoma group, follow-up was only available for 5 patients none of them showed a recurrent tumor or development of a leiomyoma in another anatomic location with a follow-up time of at least 4 years. Follow-up for patients suffering from leiomyoma with bizarre nuclei was available in seven cases. No disease recurrence occurred with a follow-up between 14 and 105 month (median 66 month).

In the leiomyosarcoma group, follow-up was available in five patients all of them died of disease. One patient was lost in follow-up after metastasectomy and for two patients no follow-up was available.

\section{Macroscopic Features}

All leiomyomas were well circumscribed. These tumors showed a homogenous gray white color and a firm, rubbery consistency with the exception of hormonally treated leiomyoma, and one leiomyoma with bizarre nuclei. The leiomyomas with bizarre nuclei (Table 2: pt.1) revealed a more yellowish cut surface and a softer consistency. Hormonally treated leiomyomas additionally demonstrated areas of hemorrhage and infarction.

All leiomyosarcomas were less well circumscribed grossly. They were characterized by a softer consistency and on cut surface the color varied from 
gray to cream. In the majority of leiomyosarcomas, necrosis appearing as yellow or green areas and red to brown areas of hemorrhage were present (Table 3).

\section{Microscopic Features}

Ten evaluated leiomyomas showed classic morphologic features. The tumors were composed of intersecting fascicles of spindle cells. The spindle cells showed bland elongated nuclei with blunt ends and eosinophilic cytoplasm. Nuclear atypia, necrosis, and mitotic activity were not present (Table 1: pts.1-7a and Figure 1a). One leiomyoma showed prominent vascularity and an edematous matrix (Table 1: pt.8).

The hormonally treated/infarcted leiomyomas (Table 1: pts.9-13) showed identical morphology to the leiomyomas of usual type; however, areas of ischemic necrosis were always seen. Ischemic-type necrosis was defined as an area of necrosis surrounded by a zone of granulation tissue and hyalinized tissue typical for ischemia (Figure 1b). The cellular leiomyoma (Table 1: pt.14) showed classic morphologic features; however, the cellularity was significantly higher than that in usual leiomyomas. In two otherwise usual leiomyomas (Table 1: pts. 15, 7b), very focal cells with nuclear, degenerative atypia were seen, and one of these was associated with a bilateral ovarian teratoma (Table 1: pt.7b). Leiomyoma with very focal atypia was defined by only very few isolated tumor cells with degenerative-type atypia in an otherwise classic leiomyoma background (Figure 1c).

All 13 leiomyomas with bizarre nuclei were characterized by the presence of cells with enlarged and pleomorphic nuclei. In all cases, the bizarre nuclei were interspersed with bland smooth muscle cells. Multinucleated tumor cells were present
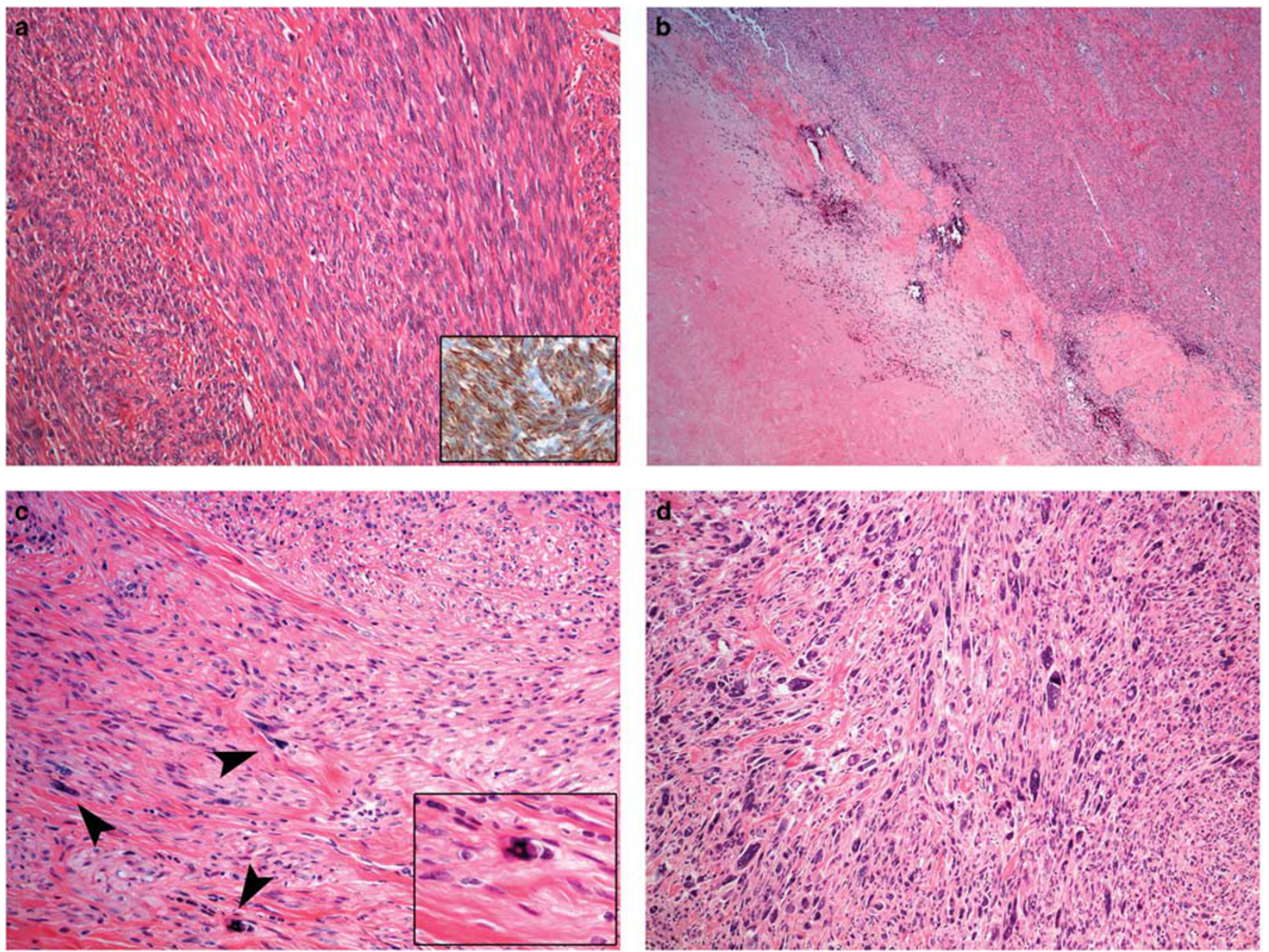

Figure 1 (a) Classic example of a leiomyoma with expression of Desmin (inset). (b) Leiomyoma after the Lupron treatment. Ischemic-type necrosis surrounded by a zone of granulation tissue and hyalinized tissue typical for ischemia. (c) Leiomyoma with very focal atypia showing isolated atypical cells within an otherwise classic leiomyoma. Cell with degenerative atypia (inset). (d) Leiomyoma with bizarre nuclei with enlarged and pleomorphic cells recognizable at low power examination. (e) Leiomyoma with bizarre nuclei: cells with enlarged nuclei with coarse chromatin, occasional pleomorphic nuclei with 'smudged' (degenerative type) chromatin pattern, nuclear pseudo inclusions, and abundant eosinophilic cytoplasm. (f) Leiomyosarcoma: cells with nuclear atypia and brisk mitotic activity. (g) Leiomyosarcoma: SMA expression by immunohistochemistry (h) Leiomyosarcoma: Desmin expression by immunohistochemistry. 

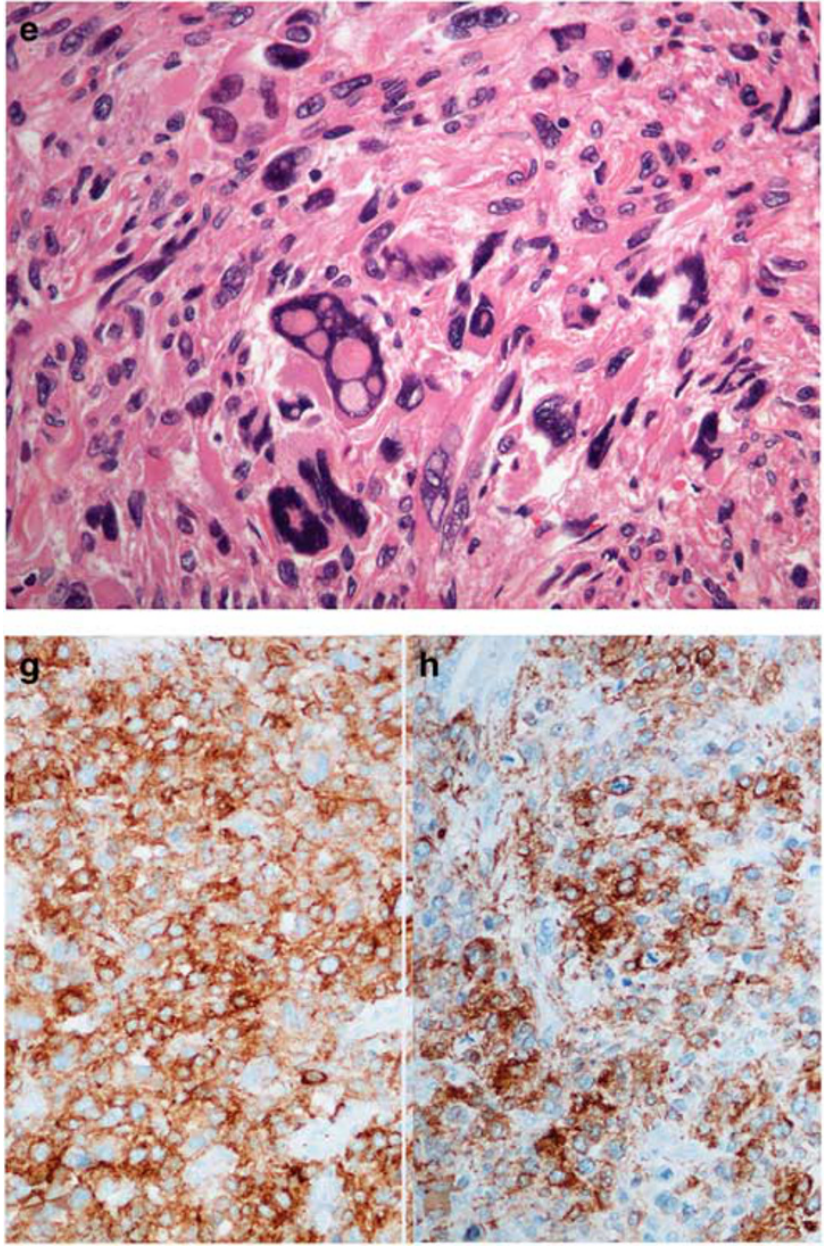

Figure 1 Continued.

focally. The atypical cells were distributed diffusely throughout the lesion. The pleomorphic cells were recognizable at low power examination $(10 \times$ objectives) (Figure 1d). The nuclei were enlarged with coarse chromatin and occasional pleomorphic nuclei with 'smudged' (degenerative type) chromatin pattern. Nuclear pseudo inclusions were also seen. The cells had abundant eosinophilic cytoplasm (Figure 1f). Mitotic figures ranged from 1 to 5 per 10/hpf (median 2 mitoses/10 hpf). A division figure was considered to be definitive if a mitotic spindle was recognized or hairy or spiky projections emanated from a central chromatin clot. Atypical mitotic figures were not present. Coagulative tumor cell necrosis was absent (Table 2).

Two leiomyosarcomas showed an infiltrative growth pattern (Table 3: pt.4 and 7), two were seen as consult cases, and in these cases the tumor margins could not be evaluated (Table 3: pt.1-2). The remaining leiomyosarcomas did not show infiltrative margins. The vast majority of the analyzed leiomyosarcomas and leiomyosarcoma metastases were composed purely of spindle cells. The spindle cells were arranged in interlacing fascicles, and the nuclei showed moderate to severe nuclear atypia. Nuclear atypia was defined by

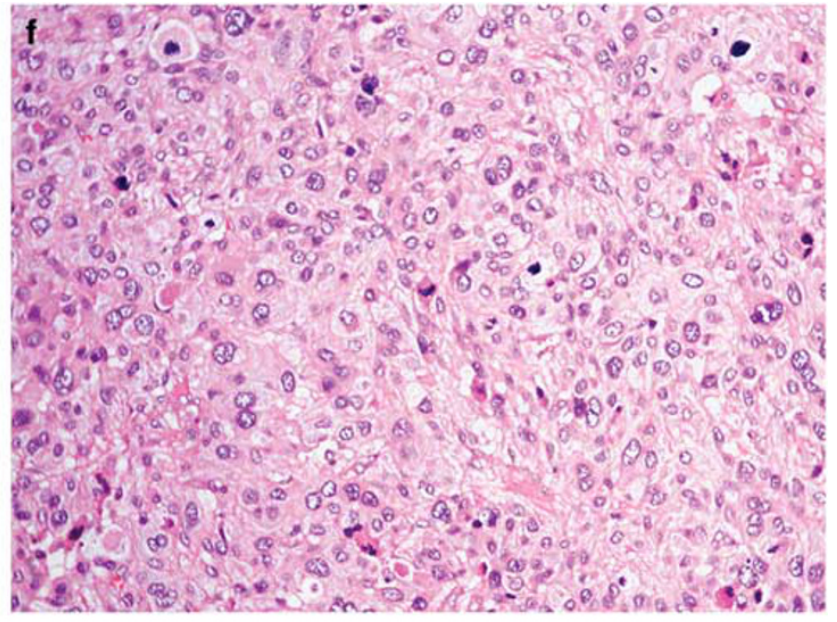

the presence of nuclear pleomorphism, nucleomegaly, nuclear membrane irregularity, hyperchromatism, and prominent nucleoli notably at low power, $10 \times$ objective (Table 3 and Figure 1f). One leiomyosarcoma showed prominent osteoclastic giant cells (Table 3: pt.2) and another one had epithelioid morphology with clear cell changes (Table 3: pt.3). One leiomyosarcoma (Table 3: pt.4) was associated with an endometrioid adenocarcinoma, diagnosed at the time of hysterectomy. Coagulative tumor cell necrosis defined as necrotic areas with a geographic appearance, atypical ghost cells within the necrosis, sharp interface between viable, and necrotic areas were seen in all cases with one exception (Table 3: pt.5). Mitotic figures ranged from 2 to 43 per 10/hpf (median 25 mitotic figures/ $10 \mathrm{hpf}$ ). All leiomyosarcomas were high-grade (G3) tumors. None of the investigated tumors showed vascular invasion.

\section{Immunohistochemistry}

All smooth muscle tumors leiomyomas, leiomyomas with bizarre nuclei and leiomyosarcomas strongly expressed SMA (Figure 1g), and in addition, at least 
focal to multifocal Desmin (Figure 1a (inset) and h) and/or h-caldesmon. The leiomyosarcoma with focal epithelioid morphology and clear cell changes (Table 3: pt:3) lacked the nuclear features of melanoma cells, merged with more typical spindled smooth muscle cells and did not express melanocytic markers like S100, HMB45, and Melan A.

\section{Array CGH of Leiomyomas, Leiomyomas with Bizarre Nuclei, and Leiomyosarcomas}

In order to assess genomic alterations at a genomewide level, we performed array-CGH. By comparing the three different entities, a continuous increase of the mean cumulative size of unbalanced genomic regions from leiomyomas (mean $4.7 \%$, range $0-17.1 \%$ of aberrant regions, compared to leiomyomas with bizarre nuclei and $P=0.0002$ to leiomyosarcomas) to leiomyomas with bizarre nuclei nuclei (mean $14.6 \%$, range $1.2-36.0$ of aberrant regions, $P=0.0229 \mathrm{com}-$ pared to leiomyosarcomas), and leiomyosarcomas (mean $28.6 \%$, range $1.0-51.9 \%$ of aberrant regions) was observed (Figure 2). In order to identify recurrent copy number alterations in the different tumor types, we subjected our data to the GREVE algorithm. Relative abundance of copy number alterations of leiomyomas, leiomyomas with bizarre nuclei, and leiomyosarcomas are demonstrated in Figure 3. Common changes across all analyzed entities were losses of chromosomes 19q and 22q.

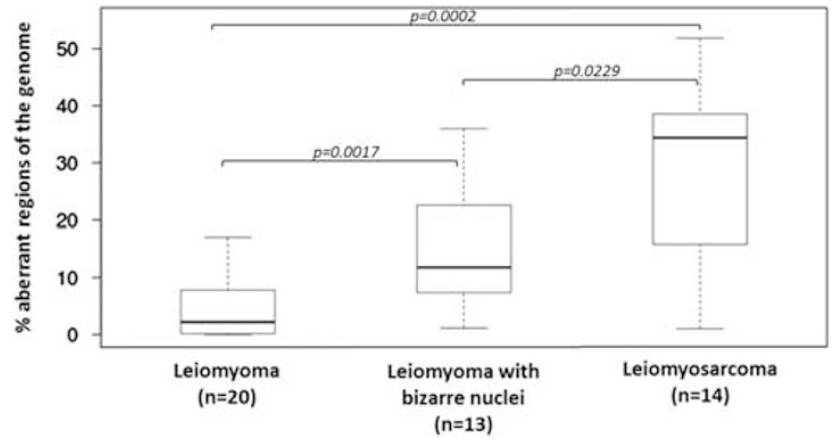

Figure 3 Comparison of the percentage of aberrant genomic regions for leiomyoma, leiomyoma with bizarre nuclei, and leiomyosarcoma. $P$ values were calculated in $\mathrm{R}$ using the wilcox. test function. a

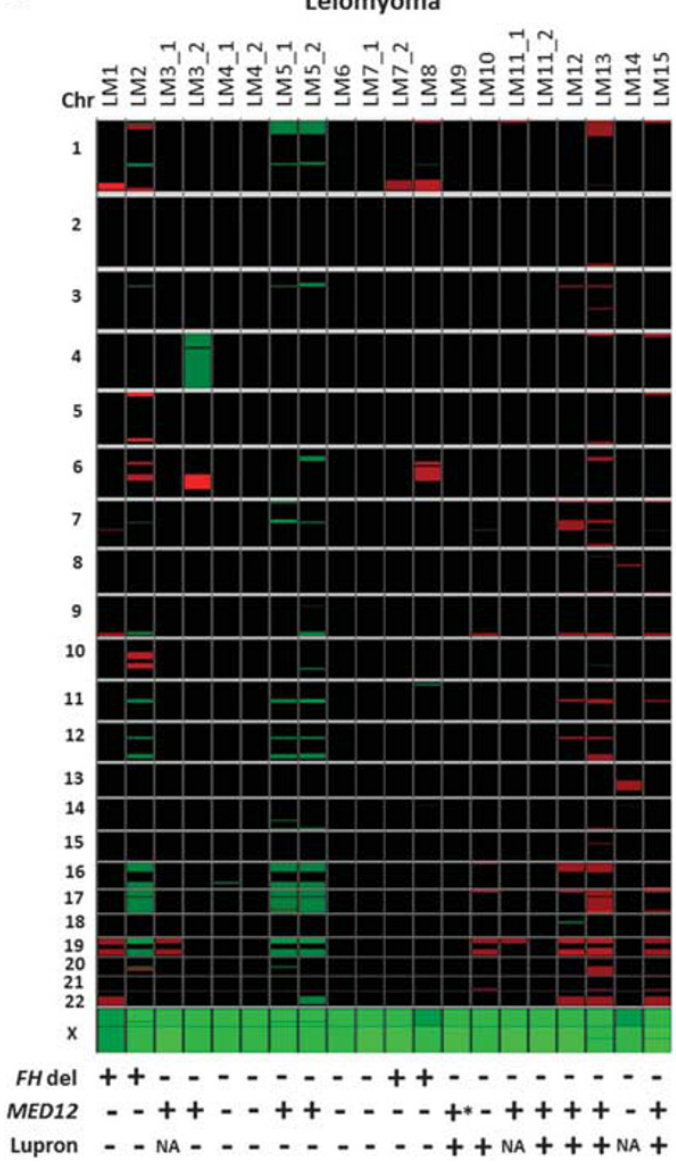

b

Leiomyoma with bizarre nuclei

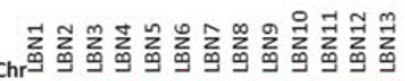
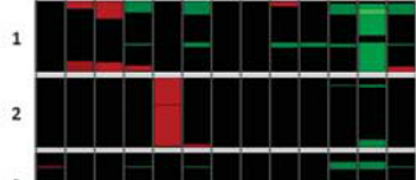

3

4

5

$$
6
$$

$$
{ }^{6}
$$$$
\begin{aligned}
& 7 \\
& 8
\end{aligned}
$$$$
\begin{aligned}
& 8 \\
& 9
\end{aligned}
$$

$$
\begin{array}{r}
9 \\
10
\end{array}
$$

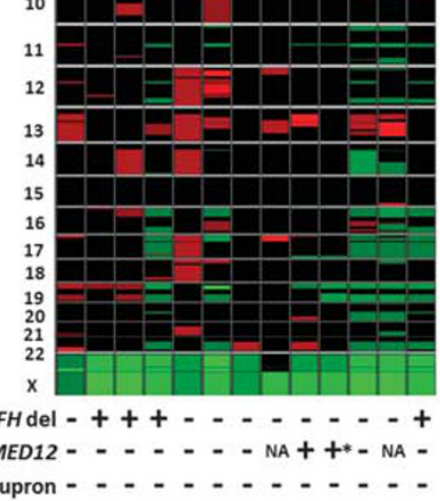

C Leiomyosarcoma

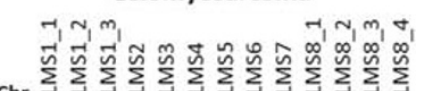

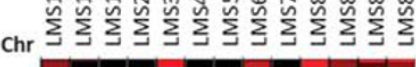

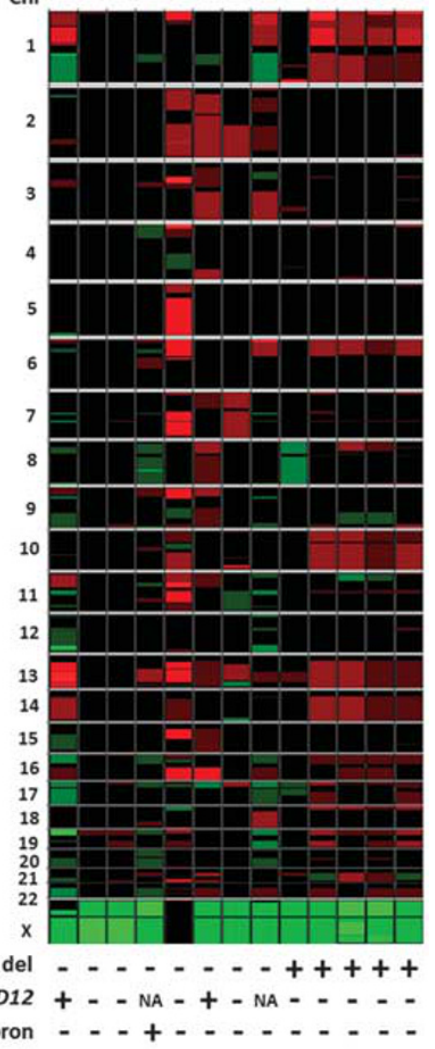

Figure 2 Heat maps of copy number profiles from array-CGH from (a) leiomyoma, (b) leiomyoma with bizarre nuclei, and (c) leiomyosarcoma (black: balanced; red: under-represented; green: over-represented). Presence/absence of FH deletions, MED12 mutations, or a history of Lupron treatment is indicated by $+/-$. NA, not available. 
Changes in Leiomyomas. Copy number alterations were identified in 16 of $20(80 \%)$ leiomyomas, the remaining samples $(4 / 20,20 \%)$ did not harbor any detectable copy number changes. In general a low number of gains and losses were noted. Among leiomyomas the most frequent changes $(\geq 20 \%$ of cases) were losses on chromosomes 1q, 7q, 19 and 22, and gains on chromosomes $1 \mathrm{q}$ and 16 (Figure 1). The only recurring alteration that was found in $\geq 30 \%$ of cases was a loss of chromosome 19 material.

Homozygous losses were found on 1q43 (1/20 cases), high-level amplifications were detected in Xq22.3 (2/20 cases) and in Xp11.3-p11.23 (1/20 cases)

The two cases of leiomyoma with very focal atypia (Table 1: pts. 15, 7b) as well as the cellular leiomyoma (Table 1: pt.14) demonstrated similar genetic changes as those of usual leiomyoma. Indeed the leiomyomas with very focal atypia (Table 1: pt.7b) did not show any genetic changes. Deletions of $1 \mathrm{q}$ were not seen (summary see Figure 4a). Six leiomyomas with a history of lupron treatment demonstrated minimal genomic alterations and clustered together with usual leiomyoma without any treatment (Figure 5).
Different tumor samples obtained from one tumor nodule or tumor samples from individual tumor nodules from one patient clustered together, ie, leiomyoma 11_1 and leiomyoma 11_2; leiomyoma 7_1, and leiomyoma 7_2; leiomyoma 4_1 and leiomyoma 4_2 (Table 1) indicating only a limited inter-tumoral and intra-tumoral heterogeneity in a given patient (Figure 5). The exception was pt. 3 with 2 samples obtained from different tumors leiomyoma 31 and leiomyoma 32 (Table 1 ) that clustered in different branches (Figure 5).

Changes in Leiomyomas with Bizarre Nuclei. All but one leiomyoma with bizarre nuclei (Table 2: pt.7) of the 13 cases of leiomyoma with bizarre nuclei had high number of copy number alterations. The most frequent changes occurring in $\geq 30 \%$ of leiomyomas with bizarre nuclei were losses on chromosomes 1q, 13, and gains on chromosomes 1p, 1q, 3p, 7p, 9q, 11q, 16p, 17p, 17q 19p, 19q, and 22 (Figure 4b).

Homozygous losses were found on 13q14.2-q14.3 (4/13 cases), 13q14.11 (1/13 cases), and 17p13.1, high-level amplifications were found on Xp11.3p11.23 (5/13 cases), 6p22.1 (1/13 cases), and in 19p.

a

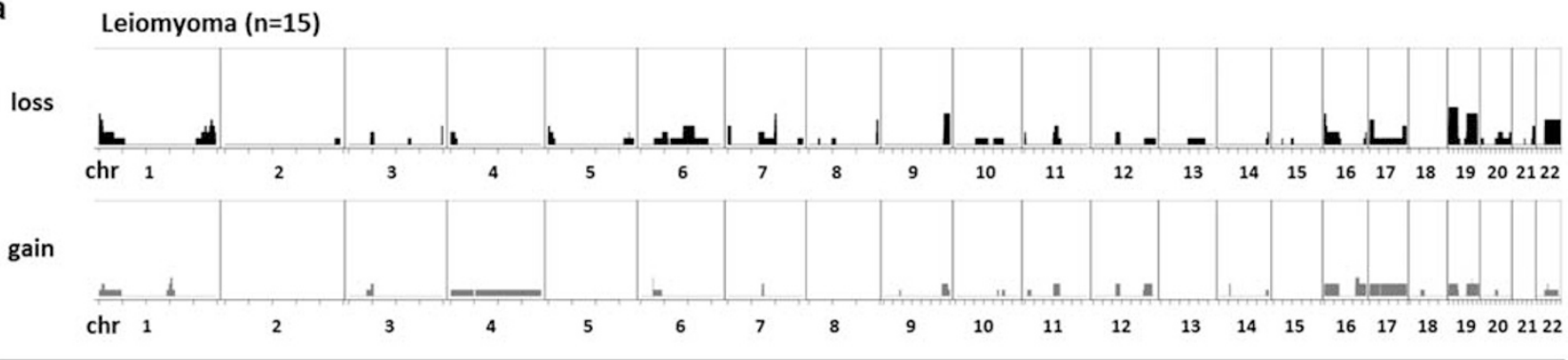

b

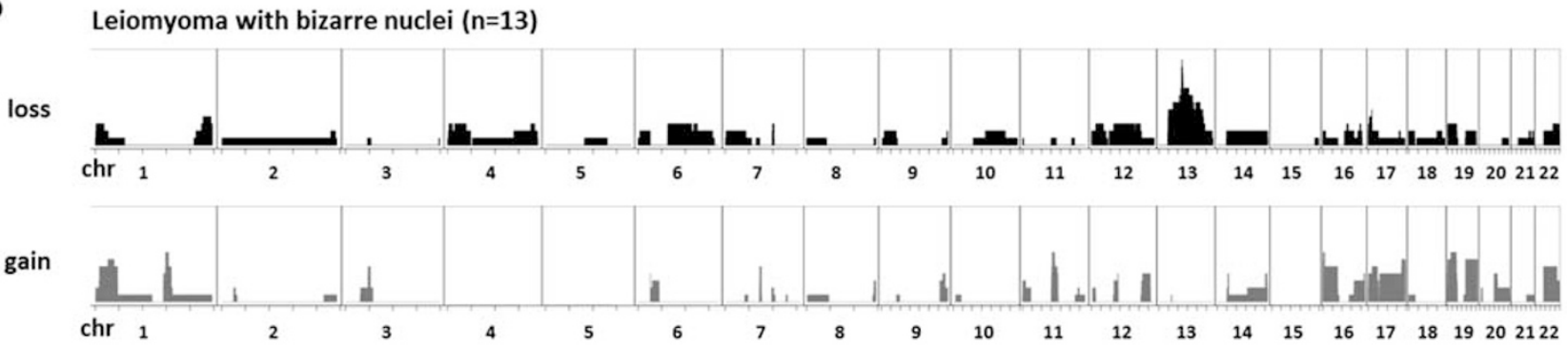

c

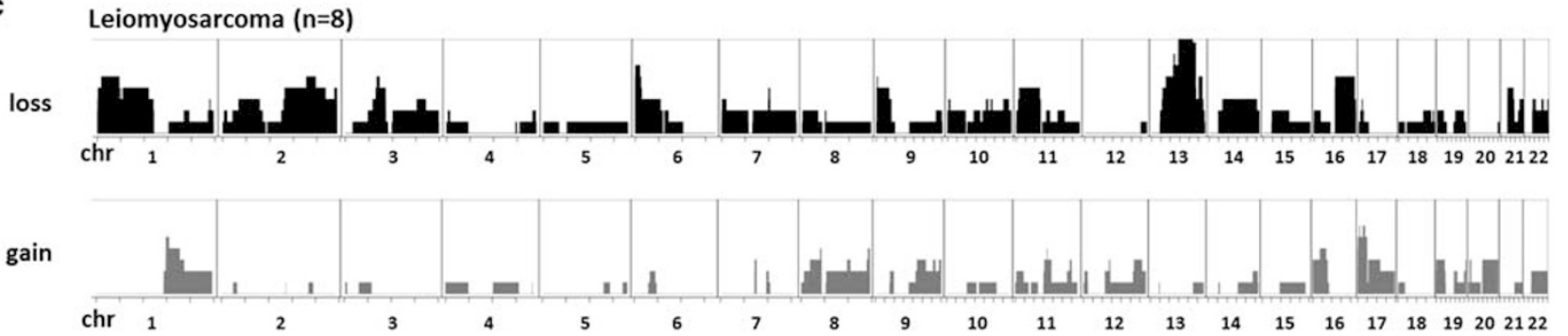

Figure 4 Relative abundance of copy number alteration of (a) leiomyoma, (b) leiomyoma with bizarre nuclei, and (c) leiomyosarcoma calculated with GREVE algorithm. Blue indicates losses of chromosomale regions; red indicates gain of chromosomal regions. 
Changes in Leiomyosarcomas. In all 14 leiomyosarcomas multiple gains and losses were identified. Deletions were, in general, more frequent than gains. The most frequent changes occurring in $\geq 30 \%$ of cases were losses on chromosomes $1 p, 3 p, 6 p, 7 p, 8 q$, $9 p, 10 q, 13,14,16,17,19,20$, and 21 , and gains on chromosomes 1q, 7q, 8q, 9q, 11q, 16p, 17q, and 19q (Figure 3). Homozygous losses were detected on 13q14.2-q14.3 (1/14 cases), 1p33 (3/14 cases) 9p24.3 (1/14 cases), 9p21.3 (1/14 cases), 14q24.1 (1/14 cases), Xq11.1-q28 (2/14 cases), 1p43 (2/14 cases), 2q37.3 (1/14 cases), 13q12.11 (1/14 cases), 13q14.2 (1/14 cases), 17p13.3 (1/14 cases), 17p13.2 (1/14 cases), 17p13.1-p12 (1/14 cases), and 22q11.23-q12.1 (1/14 cases), high-level amplifications were found on 4 q35.1 (2/14 cases) and on $+19 p$ (1/14 cases) (Figure 4c).

By comparing a primary uterine leiomyosarcoma and the subsequent metastases (leiomyosarcoma 1_1, leiomyosarcoma 1_2, leiomyosarcoma 1_3) (Table 3: pt.1), array CGH revealed a high frequency of gains and losses on the primary tumor, whereas the metastases demonstrated limited genetic changes (Figure 4c).

To explore intra-tumoral heterogeneity in a leiomyosarcoma, multiple areas from the tumor (leiomyosarcoma 8_1-leiomyosarcoma 8_4 (Table 3: pt.8) were sampled and analyzed.

Mostly similar copy number alterations were observed in all four samples. However, a distinct pattern at chromosomes 8p, 9q, 11p, 16q, and 21 for leiomyosarcoma 8_2 and leiomyosarcoma 8_4 compared to leiomyosarcoma 8_1 and leiomyosarcoma 8_3 were observed, indicating intra-tumoral heterogeneity (Figure 4c).

By evaluating copy number alterations in smooth muscle tumors, a clear separation of leiomyomas, leiomyomas with bizarre nuclei, and leiomyosarcomas was not possible. Even in smaller clusters leiomyomas, leiomyomas with bizarre nuclei and leiomyosarcomas branched together suggesting that the three histologically different entities cannot be distinguished based on copy number profiling. However, copy number alterations revealed obvious genetic similarities between leiomyomas with bizarre nuclei and leiomyosarcomas. In general, leiomyosarcomas showed a similar pattern of gains and losses as leiomyomas with bizarre nuclei, with additional copy number alterations and more homozygous losses, and high-level amplifications in leiomyosarcomas (Figure 3).

\section{MED12 Mutations and FH Deletions in Leiomyomas, Leiomyomas with Bizarre Nuclei and Leiomyosarcomas}

We sequenced exon 2 of the MED12 gene, where the most frequently mutated codon 44 is located. In addition, we used array-CGH data to screen for deletions of the $\mathrm{FH}$ gene located on chromosome 1q43.

Mutations in MED12 were identified in seven patients with leiomyoma (7/15, 47\%), affecting codon 44 in six cases, affecting codon 36 in one, and involved intronic deletion of $10 \mathrm{bp}$ also in one case (Table 1). It is noteworthy that except for leiomyoma 3 (Table 1: pt.3), all tumor samples from the same tumor nodule or from different tumor nodules of an individual patient showed the same mutation. In five patients, two samples from the same tumor (Table 1: pt.11) or two samples from two separate tumor nodules (Table 1: pts. $3,4,5,7$ ) were investigated. In three of those patients, MED12 mutations were detected. Samples leiomyoma 5 and 11

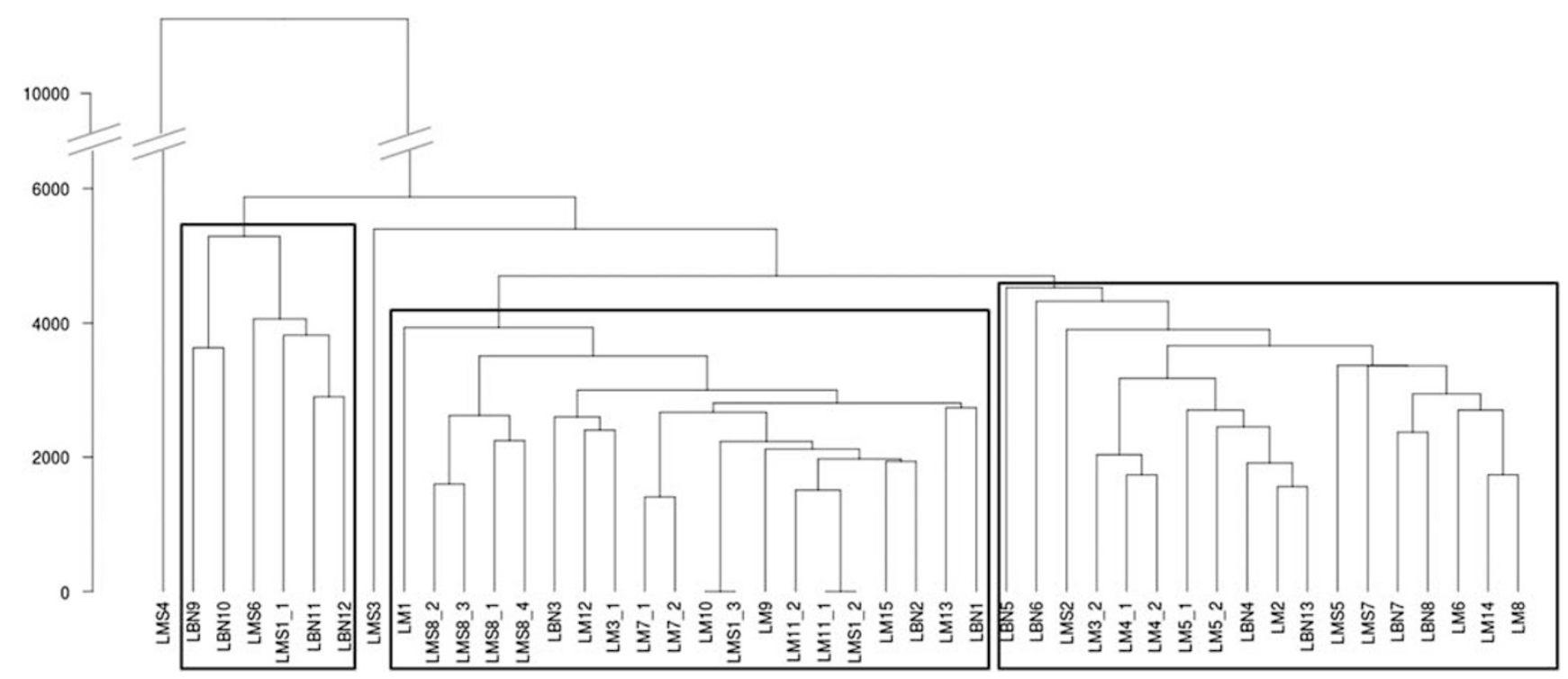

Figure 5 Hierarchical cluster analysis (Manhattan distances of copy number profiles) with leiomyoma, leiomyoma with bizarre nuclei, and leiomyosarcoma. 
demonstrated the identical MED12 mutation (Table 1: pt.5, pt.11), whereas in sample leiomyoma 3 (Table 1: pt.3), two different point mutations affecting the same codon were observed (G44V and G44D) (Table 1: pt.3). Leiomyoma with bizarre nuclei did not show any MED12 codon 44 hotspot mutations. However, in two patients (15\%), a missense mutation of codon 41 (c.122T $>$ C, p.V41A) and a synonymous mutation of codon 52 (c.156T $>$ C, p. $(=)$ ), respectively, were observed (Table 2: pts. $9,10)$. Only two out of the eight leiomyosarcoma patients $(25 \%)$ (Table 3: pts.1, 4) showed a codon 44 mutation. Interestingly, in one patient with leiomyosarcoma (Table 3: pt.1) from whom three independent tumor samples (leiomyosarcoma 1_1:primary tumor, leiomyosarcoma 1_2 and leiomyosarcoma 1_3: metastases after 4a and 7a) were available, only the primary tumor showed a MED12 mutation. In the subsequent metastases, no MED12 mutation was identified (Table 3: pt.1).

Deletions of the $F H$ gene were identified in $4 / 15$ $(27 \%)$ patients with leiomyomas. In one of these patients (Table 1: pt.7), two independent tumor lesions were available one harboring the deletion, whereas the other lesion did not show any copy number alteration. In leiomyomas with a prior history of lupron therapy, $F H$ deletions were not observed.

Furthermore, $F H$ deletions were identified in 4/13 patients $(30,8 \%)$ with leiomyomas with bizarre nuclei (Table 2) and in 2/8 patients (25\%) with leiomyosarcomas (Table 3), respectively. All four lesions from the same leiomyosarcoma from one patient showed the deletion (Table 3: pt.8_1-4).

Although a calculation of absolute copy numbers from log2-ratios is not possible due to varying amounts of tumor cells and the contamination of normal cells, an estimation of FH copy numbers revealed that except for one leiomyosarcoma all deletions were heterozygous.

It is noteworthy that MED12 mutations and $F H$ deletion occurred mutually exclusive.

\section{Discussion}

Despite recent technical advances, the etiology of uterine smooth muscle tumors has not been established and a molecular fingerprint or biomarkers to reliably distinguish morphologically challenging cases of uterine smooth muscle tumors are not available. Despite tremendous efforts subtyping, uterine smooth muscle tumors continues to rely on purely morphologic criteria including nuclear atypia, number of mitotic figures per $10 \mathrm{hpfs,} \mathrm{and} \mathrm{tumor}$ cell necrosis. ${ }^{3}$ The lack of good surrogate markers, presence of unusual histologic features, interobserver variability, and impact of a variety of hormonal therapies on the morphology of the lesions can complicate clear distinction between these tumors. As a precaution, given the fact that a vast majority of leiomyosarcomas develop in older patients, a diagnosis of leiomyosarcoma should be made in women up to the end of the fourth decade of life, only after excluding that the increased mitotic activity and/or tumor cell necrosis may have been induced by hormonal therapies. From a cytogenetic point of view, uterine smooth muscle tumors are a very heterogeneous group and driver mechanisms for the development of uterine leiomyoma subtypes, leiomyomas with bizarre nuclei, and leiomyosarcomas remain to be elucidated. Nevertheless, highthroughput sequencing in combination with genetic and cytogenetic data has laid the basis for molecular classification of uterine leiomyomas. ${ }^{35,36,42}$ The only known common oncogenic mechanism shared by benign and malignant smooth muscle tumors are mutations in MED12 (refs 24-26,31,35) that are frequently detected in uterine leiomyomas and to a much lesser extent in atypical uterine smooth muscle tumors and uterine leiomyosarcomas, respectively.

In addition, it is still under debate whether or not benign smooth muscle tumors of the uterus have the potential for malignant transformation into leiomyosarcoma. In a 2004 study, distinct cytogenetic and molecular genetic pathways were noted for leiomyomas and leiomyosarcomas. ${ }^{43}$ Therefore, a vast majority of leiomyosarcomas has been presumed to arise de novo; progression from leiomyoma to leiomyosarcoma has been considered unlikely. In 2009, a study by Mittal et al ${ }^{44}$ raised the possibility that leiomyosarcoma may be derived from leiomyoma.

The primary objective of our study was the assessment of genome-wide copy number alterations and other common molecular changes in a wellcharacterized group of uterine smooth muscle tumors in order to identify potential surrogate makers that might aid in the diagnosis of these morphologic challenging tumor entities. In addition, a main goal was to explore if there is evidence for transformation from leiomyoma with bizarre nuclei and/or leiomyoma to leiomyosarcoma.

We detected copy number alterations in more than $90 \%$ of analyzed samples. However, copy number alteration profiling did not reveal any distinctive pattern that might allow a clear separation between the benign leiomyoma subtypes including classic leiomyoma, hormonally treated leiomyoma, cellular leiomyoma, leiomyoma with bizarre nuclei, and leiomyosarcoma.

In contrast, genetics changes such as losses at chromosomes 19 and 22 were commonly observed across all lesions. This cytogenetic profile was previously found in $\sim 3 \%$ of uterine leiomyoma. ${ }^{19}$ In a study from Nucci et $a l^{45}$ pulmonary-based smooth muscle tumors were found to harbor consistent chromosomal aberrations $(19 \mathrm{q}$ and $22 \mathrm{q}$ terminal deletion) in all cases suggesting a key pathogenetic role for sequential tumor suppressor inactivation events. This is in line with our findings 
as these specific copy number changes were also found in leiomyomas with bizarre nuclei and leiomyosarcomas indicating that these lesions may share a common pathogenetic mechanism. Furthermore, when we performed the hierarchical cluster analysis, these tumors branched together even in smaller sub-clusters indicating that these histologically different entities cannot be distinguished based on copy number profiling. In concordance with the literature, leiomyosarcomas typically demonstrated the highest frequency of copy number alterations, ${ }^{19,29,46}$ whereas leiomyomas showed a low number of copy number alterations with a few cases $(20 \%)$ lacking any gains or losses. Interestingly, all cases of leiomyomas with bizarre nuclei and leiomyosarcomas showed a high number of copy number alterations involving nearly all chromosomes. Although leiomyosarcomas showed significantly more copy number alterations with more homozygous losses and higher level of amplifications than leiomyomas with bizarre nuclei, we observed marked similarities in copy number alteration pattern especially between leiomyomas with bizarre nuclei and leiomyosarcomas. A chromosome that was frequently deleted in cases of leiomyomas with bizarre nuclei and leiomyosarcomas was chromosome 13q. In our samples, deletions on chromosome $13 q 14.2$ occurred in $79 \%$ of leiomyosarcoma cases and in $54 \%$ of leiomyomas with bizarre nuclei. Interestingly, this region harbors the tumor suppressor $R B 1$. The involvement of $R B 1$ in pathogenesis of different malignancies as well as a role for $R B 1$ in leiomyosarcoma is a frequent reported finding. ${ }^{4-49}$ In contrast, a loss in $13 \mathrm{q}$ was only detected in a single leiomyoma indicating a potential use of intact $\mathrm{RB}$ as a surrogate marker for leiomyomas. Confirmation of this finding in a larger number and variety of leiomyomas is warranted. Other shared gains and losses between these two subgroups were losses on chromosome 1 and 13, and a gain on chromosome $1 \mathrm{q}, 7 \mathrm{q}, 16,17 \mathrm{q}$, and 20 . The most important differences between leiomyomas with bizarre nuclei and leiomyosarcomas were losses on chromosomes 3, $6,10,14$, and 21, which were frequently found in leiomyosarcomas, but not in leiomyomas with bizarre nuclei.

The overlapping genomic alterations seen in leiomyomas with bizarre nuclei and leiomyosarcomas suggest that these tumors may develop through similar genetic pathways, and that leiomyomas with bizarre nuclei might have a potential to progress into leiomyosarcomas with time and after acquisition of additional alterations. ${ }^{3,44,50}$ It is important to emphasize that despite these common chromosomal alterations leiomyomas with bizarre nuclei are classified as clinically benign smooth muscle tumors rather than 'pre-malignant' conditions. Patients' age at diagnosis greatly differs for leiomyomas with bizarre nuclei and leiomyosarcomas with 41 and 55 years, respectively. Thus, one could suggest a potential time-based relationship, a 'pre-malignant' condition, would need to progress to cancer. ${ }^{31,36,37}$ However, the vast majority of leiomyoma with bizarre nuclei is treated by hysterectomy and is excised before a putative transformation into clear-cut leiomyosarcoma could occur. Large multicenter studies following patients with leiomyoma with bizarre nuclei over a period of time without surgical treatment to investigate their biology are lacking. The presented findings of copy number alterations in our study challenge the widely accepted concept that leiomyoma with bizarre nuclei, synonym 'pleomorphic/symplastic' leiomyoma (former also known as atypical leiomyoma according to the WHO 2003) is a variant of leiomyoma with marked degenerative cellular (nuclear) changes. On the basis of our findings, the morphologic changes most likely do not reflect just simple 'degenerative' alterations but reflect severe chromosomal abnormalities not seen in usual leiomyomas.

Recently MED12 mutations have been shown in benign, atypical, and malignant smooth muscle tumors as the first recurrent oncogenic mechanism indicating a general relevance of MED12 mutations in the pathogenesis of tumors with smooth muscle differentiation. ${ }^{34}$

Sequencing of exon 2 of the MED12 gene, where the most frequently mutated codon 44 is located, revealed mutations in $47 \%$ of cases in the leiomyoma group in our study. This is in concordance with the literature reporting MED12 mutations in frequencies between 48 and $92 \% .{ }^{36}$ Our study included an expanded spectrum of leiomyoma subtypes and the results clearly demonstrate that MED12 mutations can occur in all leiomyoma subtypes investigated irrespective of the tumor size. All diagnostically challenging leiomyomas with a prior history of lupron treatment demonstrated a MED12 mutation and minimal genomic alterations demonstrating no significant differences to usual leiomyomas.

In contrast to leiomyomas, only $15 \%$ of leiomyomas with bizarre nuclei showed mutations in exon 2 of the MED12 gene. Interestingly, all mutations were located outside the hotspot region suggesting expansion of mutational screening in this subtype might provide further insights.

Furthermore, similar to previous reports where MED12 mutations were seen infrequently (10-15\%) in leiomyosarcomas. ${ }^{39,51}$ Overall, $25 \%$ of patients suffering from leiomyosarcomas in our study demonstrated a MED12 codon 44 mutations in the primary tumor. Surprisingly, in a patient (leiomyosarcoma1) with two subsequent leiomyosarcoma metastases that occurred 4 and 7 years after initial diagnosis MED12 mutation was no longer detectable in the metastases indicating that a tumor cell clone lacking MED12 mutation could have metastasized.

Moreover, despite a high frequency of gains and losses in the primary tumor, limited genetic changes were seen in the metastases. Although a lower complexity of genetic changes in metastases 
compared to primary tumors has been described in solid tumors, ${ }^{52}$ there are no data available for leiomyosarcomas. One possible explanation could be intra-tumoral heterogeneity suggesting that the metastatic clone was not discovered in the primary specimen as well as the tumor microenvironment.

In our study, MED12 mutations in leiomyomas with bizarre nuclei and leiomyosarcomas were infrequent and in leiomyomas with bizarre nuclei exclusively found outside of the hotspot areas. Therefore, it seems to be unlikely that MED12 mutations have a crucial role in possible 'linear progression' of leiomyoma and leiomyoma with bizarre nuclei into leiomyosarcoma. Therefore it is questionable, whether MED12 acts as a driver mutation in the development of leiomyoma with bizarre nuclei and leiomyosarcoma.

The present study also investigated the presence of FH deletion, another proposed driver mutation in leiomyoma. FH deletions occurred in $27 \%$ of usual leiomyomas, $30.8 \%$ of leiomyomas with bizarre nuclei, and $25 \%$ of leiomyosarcomas, thus clearly demonstrating another common genetic change in this tumor group. To the best of our knowledge, this is the first report of $F H$ deletion occurring in all subtypes of uterine smooth muscle tumors. In addition, the frequency of $F H$ deletion in our group of leiomyomas was higher than initially reported. ${ }^{36}$ In concordance with the literature, MED12 mutations and FH deletions were mutually exclusive in leiomyoma ${ }^{36}$ as well as leiomyoma with bizarre nuclei and leiomyosarcoma.

In order to investigate inter- and intra-tumoral heterogeneity, we analyzed two or more samples from the same patients and compared the copy number alterations pattern, MED12 mutations and $\mathrm{FH}$-deletions. In leiomyoma group different tumor samples obtained from one tumor nodule or tumor samples from separate tumor nodules from the same patient clustered together indicating only a limited inter-tumoral and intra-tumoral heterogeneity in a given patient. The exception was a single patient with two independent leiomyoma nodules that clustered in different branches and revealed different MED12 mutations in the same codon (G44V vs G44D). Exploring $F H$ deletion in more than one leiomyoma of a patient revealed a case with intertumoral heterogeneity. However, exploring interand intra-tumoral heterogeneity was limited by the small sample size.

Furthermore, the analysis of individual tumor areas within one large leiomyosarcoma revealed several differences in the copy number alteration profile indicating the presence of an intra-tumoral heterogeneity. Moreover, one patient showed heterogeneity with respect to $F H$ deletions. However, due to the limited availability of several samples from the same patients, we were not able to draw any significant conclusions with respect to inter- and intra-tumoral heterogeneity.
In conclusion, our study demonstrates that by evaluating copy number alterations in smooth muscle tumors a clear separation between benign and malignant smooth muscle tumors is not possible. However, copy number alterations revealed marked genetic similarities between leiomyomas with bizarre nuclei and leiomyosarcomas challenging the common concept that a leiomyoma with bizarre nuclei (synonyms: 'pleomorphic/symplastic' leiomyoma and previously termed atypical leiomyoma according to the WHO 2003) is a smooth muscle tumor with degenerative cellular changes and without relationship to leiomyosarcoma. The genetic profile demonstrates that morphologic changes in leiomyomas with bizarre nuclei might not reflect just simple 'degenerative' alterations but rather severe chromosomal abnormalities not seen in usual leiomyomas. Our findings raise the intriguing possibility that leiomyomas with bizarre nuclei may be a precursor of leiomyosarcomas. Our data and findings from two previous studies ${ }^{39,51}$ demonstrate that in contrast to leiomyomas, MED12 mutations in leiomyomas with bizarre nuclei and leiomyosarcomas do not occur frequently, and that these mutations may not act as 'driver' mutations in the development of leiomyomas with bizarre nuclei and leiomyosarcomas. To further explore the concept of tumor progression and to identify biomarkers to differentiate between diagnostically challenging uterine smooth muscle tumors, high-resolution molecular studies are needed to search for recurrent genetic changes in chromosome areas where overlap between leiomyomas, leiomyomas with bizarre nuclei, and leiomyosarcomas occur.

\section{Disclosure/conflict of interest}

The authors declare no conflict of interest.

\section{References}

1 Walker CL, Stewart EA. Uterine fibroids: the elephant in the room. Science 2005;308:1589-1592.

2 Oliva E, Young RH, Clement PB et al. Cellular benign mesenchymal tumors of the uterus. A comparative morphologic and immunohistochemical analysis of 33 highly cellular leiomyomas and six endometrial stromal nodules, two frequently confused tumors. Am J Surg Pathol 1995;19:757-768.

3 Bell SW, Kempson RL, Hendrickson MR. Problematic uterine smooth muscle neoplasms. A clinicopathologic study of 213 cases. Am J Surg Pathol 1994;18:535-558.

4 Akladios CY, Roedlich MN, Bretz-Grenier MF et al. Intracystic papillary carcinoma of the breast: a diagnostic challenge with major clinical impact. Anticancer Res 2014;34:5017-5020.

5 Croce S, Young RH, Oliva E. Uterine leiomyomas with bizarre nuclei: a clinicopathologic study of 59 cases. Am J Surg Pathol 2014;38:1330-1339.

6 Oliva E, Carcangiu ML, Carinelli SG, et al. Mesenchymal tumours. In: Kurman RJ, Carcangiu ML, Herrington CS 
et al. (eds). WHO Classification of Tumours of Female Reproductive Organs, 4th ed. IARC Press: Lyon, France, 2014, pp 135-141.

7 Hendrickson MR, Tavassoli FA, Kempson RL et al. Mesenchymal tumours and related lesions. In: Tavassoli FA, Devilee P (eds). Pathology and Genetics of Tumours of the Breast and Female Genital Organs. IARC Press: Lyon, France, 2003, pp 233-244.

8 Sreenan JJ, Prayson RA, Biscotti CV et al. Histopathologic findings in 107 uterine leiomyomas treated with leuprolide acetate compared with 126 controls. Am J Surg Pathol 1996;20:427-432.

9 Clement PB, Young RH, Scully RE. Diffuse, perinodular, and other patterns of hydropic degeneration within and adjacent to uterine leiomyomas. Problems in differential diagnosis. Am J Surg Pathol 1992;16: 26-32.

10 Myles JL, Hart WR. Apoplectic leiomyomas of the uterus. A clinicopathologic study of five distinctive hemorrhagic leiomyomas associated with oral contraceptive usage. Am J Surg Pathol 1985;9:798-805.

11 Kurman RJ, Norris HJ. Mesenchymal tumors of the uterus. VI. Epithelioid smooth muscle tumors including leiomyoblastoma and clear-cell leiomyoma: a clinical and pathologic analysis of 26 cases. Cancer 1976;37:1853-1865.

12 Toon C, McGahan S, Henderson P et al. Myxoid symplastic leiomyoma of the uterus. Pathology 2006;38:275-277.

13 Shintaku M. Lipoleiomyomatous tumors of the uterus: a heterogeneous group? Histopathological study of five cases. Pathol Int 1996;46:498-502.

14 Hsieh CH, Lui CC, Huang SC et al. Multiple uterine angioleiomyomas in a woman presenting with severe menorrhagia. Gynecol Oncol 2003;90:348-352.

15 Ferry JA, Harris NL, Scully RE. Uterine leiomyomas with lymphoid infiltration simulating lymphoma. A report of seven cases. Int J Gynecol Pathol 1989;8: 263-270.

16 Gisser SD, Young I. Neurilemoma-like uterine myomas: an ultrastructural reaffirmation of their non-Schwannian nature. Am J Obstet Gynecol 1977;129:389-392.

17 Mashal RD, Fejzo ML, Friedman AJ et al. Analysis of androgen receptor DNA reveals the independent clonal origins of uterine leiomyomata and the secondary nature of cytogenetic aberrations in the development of leiomyomata. Genes Chromosomes Cancer 1994;11: $1-6$.

18 Ligon AH, Morton CC. Leiomyomata: heritability and cytogenetic studies. Hum Reprod Update 2001;7:8-14.

19 Christacos NC, Quade BJ, Dal Cin P et al. Uterine leiomyomata with deletions of Ip represent a distinct cytogenetic subgroup associated with unusual histologic features. Genes Chromosomes Cancer 2006;45: 304-312.

20 Friedrich $\mathrm{M}$, Riffel B, Schillinger $\mathrm{H}$ et al. Uterine leiomyosarcoma with subsequent pregnancy. Zentralbl Gynakol 1998;120:341-346.

21 Harlow BL, Weiss NS, Lofton S. The epidemiology of sarcomas of the uterus. J Natl Cancer Inst 1986;76: 399-402.

22 Brooks SE, Zhan $\mathrm{M}$, Cote $\mathrm{T}$ et al. Surveillance, epidemiology, and end results analysis of 2677 cases of uterine sarcoma 1989-1999. Gynecol Oncol 2004;93: 204-208.

23 Mayerhofer K, Obermair A, Windbichler G et al. Leiomyosarcoma of the uterus: a clinicopathologic multicenter study of 71 cases. Gynecol Oncol 1999;74: 196-201.

24 Friedrich M, Villena-Heinsen C, Mink D et al. Leiomyosarcomas of the female genital tract: a clinical and histopathological study. Eur J Gynaecol Oncol 1998;19: 470-475.

25 Nordal RR, Thoresen SO. Uterine sarcomas in Norway 1956-1992: incidence, survival and mortality. Eur J Cancer. 1997;33:907-911.

26 Croce S, Ribeiro A, Brulard C et al. Uterine smooth muscle tumor analysis by comparative genomic hybridization: a useful diagnostic tool in challenging lesions. Mod Pathol 2015;28:1001-1010.

27 Ip PP, Cheung AN, Clement PB. Uterine smooth muscle tumors of uncertain malignant potential (STUMP): a clinicopathologic analysis of 16 cases. Am J Surg Pathol 2009;33:992-1005.

28 Fletcher JA, Morton CC, Pavelka K et al. Chromosome aberrations in uterine smooth muscle tumors: potential diagnostic relevance of cytogenetic instability. Cancer Res 1990;50:4092-4097.

29 Sreekantaiah C, Davis JR, Sandberg AA. Chromosomal abnormalities in leiomyosarcomas. Am J Pathol 1993; 142:293-305.

$30 \mathrm{Hu}$ J, Rao UN, Jasani S et al. Loss of DNA copy number of $10 \mathrm{q}$ is associated with aggressive behavior of leiomyosarcomas: a comparative genomic hybridization study. Cancer Genet Cytogenet 2005;161:20-27.

31 Quade BJ, Pinto AP, Howard DR et al. Frequent loss of heterozygosity for chromosome 10 in uterine leiomyosarcoma in contrast to leiomyoma. Am J Pathol. 1999;154:945-950.

32 Makinen N, Mehine M, Tolvanen J et al. MED12, the mediator complex subunit 12 gene, is mutated at high frequency in uterine leiomyomas. Science 2011;334: 252-255.

33 Perot G, Croce S, Ribeiro A et al. MED12 alterations in both human benign and malignant uterine soft tissue tumors. PLoS One 2012;7:e40015.

34 Ravegnini G, Marino-Enriquez A, Slater J et al. MED12 mutations in leiomyosarcoma and extrauterine leiomyoma. Mod Pathol 2013;26:743-749.

35 Mehine M, Kaasinen E, Makinen N et al. Characterization of uterine leiomyomas by whole-genome sequencing. N Engl J Med 2013;369:43-53.

36 Mehine M, Makinen N, Heinonen HR et al. Genomics of uterine leiomyomas: insights from high-throughput sequencing. Fertil Steril 2014;102:621-629.

37 Holzmann C, Markowski DN, Koczan D et al. Cytogenetically normal uterine leiomyomas without MED12-mutations-a source to identify unknown mechanisms of the development of uterine smooth muscle tumors. Mol Cytogenet 2014;7:88.

38 van Beers EH, Joosse SA, Ligtenberg MJ et al. A multiplex PCR predictor for aCGH success of FFPE samples. Br J Cancer 2006;94:333-337.

39 Zhang Q, Ubago J, Li L et al. Molecular analyses of 6 different types of uterine smooth muscle tumors: Emphasis in atypical leiomyoma. Cancer 2014;120: 3165-3177.

40 Cazier JB, Holmes CC, Broxholme J. GREVE: Genomic recurrent event viewer to assist the identification of patterns across individual cancer samples. Bioinformatics 2012;28:2981-2982.

41 Team RDC. A Language and Environment for Statistical Computing. R Foundation for Statistical Computing: Vienna, Austria, 2008. 
42 Mehine M, Kaasinen E, Aaltonen LA. Chromothripsis in uterine leiomyomas. N Engl J Med 2013;369: 2160-2161.

43 Quade BJ, Wang TY, Sornberger K et al. Molecular pathogenesis of uterine smooth muscle tumors from transcriptional profiling. Genes Chromosomes Cancer 2004;40:97-108.

44 Mittal KR, Chen F, Wei JJ et al. Molecular and immunohistochemical evidence for the origin of uterine leiomyosarcomas from associated leiomyoma and symplastic leiomyoma-like areas. Mod Pathol 2009;22: 1303-1311.

45 Nucci MR, Drapkin R, Dal Cin P et al. Distinctive cytogenetic profile in benign metastasizing leiomyoma: pathogenetic implications. Am J Surg Pathol 2007;31: 737-743.

46 Packenham JP, du Manoir S, Schrock E et al. Analysis of genetic alterations in uterine leiomyomas and leiomyosarcomas by comparative genomic hybridization. Mol Carcinog 1997;19:273-279.
47 Classon M, Harlow E. The retinoblastoma tumour suppressor in development and cancer. Nat Rev Cancer 2002;2:910-917.

48 Yang J, Du X, Chen K et al. Genetic aberrations in soft tissue leiomyosarcoma. Cancer Lett 2009;275:1-8.

49 Lusby K, Savannah KB, Demicco EG et al. Uterine leiomyosarcoma management, outcome, and associated molecular biomarkers: a single institution's experience. Ann Surg Oncol 2013;20:2364-2372.

50 Hernando E, Charytonowicz E, Dudas ME et al. The AKT-mTOR pathway plays a critical role in the development of leiomyosarcomas. Nat Med 2007;13: 748-753.

51 Bertsch E, Qiang W, Zhang Q et al. MED12 and HMGA2 mutations: two independent genetic events in uterine leiomyoma and leiomyosarcoma. Mod Pathol 2014;27: 1144-1153.

52 Rinner B, Galle B, Trajanoski S et al. Molecular evidence for the bi-clonal origin of neuroendocrine tumor derived metastases. BMC Genomics 2012;13:594.

Supplementary Information accompanies the paper on Modern Pathology website (http://www.nature.com/ modpathol) 